\title{
Concentration, Temporal Variation and Sources Identification of Polycyclic Aromatic Hydrocarbons (PAHs) In Olive Leaf in Bursa, Turkey
}

\author{
Fatma Esen, Mehmet Ferhat Sari and Yücel Tasdemir
}

\begin{abstract}
In this study, it was aimed to determine the seasonal distribution and possible sources of polycyclic aromatic hydrocarbon (PAH) concentrations in olive tree leaves. In this context, the sampling was conducted between January and December 2016 at the Bursa Uludag University Gemlik Campus. Total PAH ( $(12 \mathrm{PAH})$ concentration levels were found to be 729 , 431, 219 and $387 \mathrm{ng} / \mathrm{g}$ dry weight (dw) for winter (February), spring (May), summer (July) and autumn (December) seasons, respectively. The Pearson correlation coefficient (PCC) method was employed to determine temporal differences among the seasonal PAH concentrations. The coefficient of divergence (COD), diagnostic ratio (DR) and principal component analysis (PCA) methods were used to determine possible sources. According to the PCC method, PAH concentrations between winter and summer changed depending on time. The reason for temporal differences in these seasons would be the possible sources including fuels used for heating purposes and meteorological factors. According to the DR and PCA results, the most important sources of PAHs in winter, spring and autumn seasons were the combustions of biomass, domestic heating and oil production while vehicle emissions were the most important sources for PAHs in the summer.
\end{abstract}

Keywords - PAH, olive leave, air pollution, seasonal distribution, sources identification

\section{INTRODUCTION}

Polycyclic aromatic hydrocarbons (PAHs) are organic pollutants containing two or more benzene rings, many of which are carcinogenic, teratogenic, mutagenic, and toxic. Although there are some natural sources (forest fires), human activities and industries are the largest sources of PAHs emissions. Some PAH compounds are known to cause cancer in humans. The US EPA listed $16 \mathrm{PAH}$ compounds as primary pollutants because of their high carcinogenic and toxic effects [1].

It is crucial to implement atmospheric monitoring plans to assess pollutant properties, fate and behavior. Monitoring using plants is the best tool for estimating atmospheric contamination levels [2]. Plant species have been used to monitor pollutants since the 1960s. Various plants are considered to measure atmospheric pollutant concentrations. Plant usage is more economical since no special equipment is required to determine

Fatma Esen, Department of Environmental Engineering, Faculty of Engineering, Bursa Uludag University, 16059 Nilufer, Bursa, Turkey.

Mehmet Ferhat Sari and Yücel Tasdemir, Department of Environmental Engineering, Faculty of Engineering, Bursa Uludag University, 16059 Nilufer, Bursa, Turkey. atmospheric pollutant concentrations [3]. Plants are used to identify local and global pollution sources and pollution trends [4]. Tree needles/leaves provide reliable results to assess the effects of airborne pollutants such as PAHs on ecosystems and human health [5].

Olive leaves were collected in Bursa (Turkey) between January-December 2016 for analyzing PAHs. The aim of this study; i) to show the temporal changes of PAH concentrations and ii) to identify the sources of PAHs at the olive leaves.

\section{MATERIAL AND METHODS}

\section{A. Sampling Area and Sample Preparation}

Olive leaf samples were collected from the Bursa Uludag University Gemlik Campus. The sampling period was 30 days and olive tree leaf samples were taken from the sampling points for four months in order to represent the temporal fluctuations. Homogeneous samples were taken from different points of the tree for representing the whole tree. The olive leaf samples were packaged with aluminum foil and transported to the laboratory in locked bags to avoid any contamination during transport, without contact with air and kept in the freezer at $-4^{\circ} \mathrm{C}$ until analysis.

\section{B. Sampling Analysis and Instrumental Analysis}

Approximately $5 \mathrm{~g}$ of olive leaf samples were weighed and cut into small pieces and taken into amber bottles. Then, $1 \mathrm{~mL}$ of the surrogate standard was added to determine recovery efficiencies. Fifty $\mathrm{mL}$ of petroleum ether:dichloromethane (PE:DCM, v:v, 1:1) was added to the sample and placed in a shaker for 24 hours [6]. The amber flasks containing the sample solutions were placed into the ultrasonic extraction (Elmasonic S $80 \mathrm{H}$ Model, Germany) after shaker. The flasks were then placed in an ultrasonic bath and firstly held for 15 minutes. At the end of the period, the solvent was transferred into a separate flask. Forty $\mathrm{mL}$ of acetone:hexane (ACE:HEX, v:v, 1:1) was added to the flask containing the leaf sample and again it was extracted in the ultrasonic bath for 30 minutes. A rotary evaporator (Laborota 4001 Model, Heidolph, Germany) was used to reduce the volume of solution containing sample. Volume of the samples were reduced to $1 \mathrm{~mL}$ and vialed and stored in the freezer at $-20{ }^{\circ} \mathrm{C}$ until analysis. Agilent 7890A gas chromatograph (GC) and a mass spectrophotometer (MS) with Agilent 5975C inert XL triaxial mass detector were used to 
quantify PAHs. In the GC-MS, a capillary column (HP-5MS, $30 \mathrm{~m} \times 0.25 \mathrm{~mm} \times 0.25 \mu \mathrm{m}$ ) was used. The injector, ion source and quadrupole temperatures were 295,300 and $180 \mathrm{oC}$, respectively. Oven temperature program; initial oven temperature was 1 minute at $50 \mathrm{oC}$, increase to $200 \mathrm{oC}$ with an increase of $25 \mathrm{oC} / \mathrm{min}$, increase from $200 \mathrm{oC}$ to $300 \mathrm{oC}$ with an increase of $8 \mathrm{oC} / \mathrm{min}$ and wait for $5.5 \mathrm{~min}$ at $300 \mathrm{oC}$. High purity helium gas was used as the carrier gas at a constant flow rate of $1.4 \mathrm{~mL} / \mathrm{min}$. The mass spectrophotometer was operated in an ion monitoring mode selected for high sensitivity. Determination of PAH species was performed based on retention times and targeted ion peaks. Total $12 \mathrm{PAHs}$ were targeted and they were: Phenanthrene (PHE), Anthracene (ANT), Fluoranthene (FL), Pyrene (PY), benz(a)anthracene $(\mathrm{BaA})$, Chrysene (CHR), Benzo(b)flouranthene (BbF), Benzo(k)fluoranthene (BkF), Benzo(a)pyrene (BaP), Indeno(1,2,3-cd)pyren (IcdP), Dibenz[a,h]anthracene (DahA), Benzo(g,h,i)perylene (BghiP)'dir..

\section{Quality Assurance/Quality Control (QA/QC)}

The GC-MS instrument was calibrated before the PAH mass values of the samples were determined. The six-level calibration standard $(40,400,1000,4000,6000,10000 \mathrm{ng} / \mathrm{mL})$ was used to calibrate the instrument. The $\mathrm{r} 2$ values for all calibration levels were calculated as $>0.99$. In addition, after approximately 100 samples, the medium (1000 or $4000 \mathrm{ng} / \mathrm{mL}$ ) calibration standard was read and GC-MS was calibrated if necessary. Samples with recovery efficiencies between $40 \%$ and $120 \%$ were taken into account in the calculations. To determine the analytical yields of the samples, surrogate standard consisting of naphthalene-D8, acenaphthene-D10, phenanthrene-D10, chrysene-D12 and perylene-D12 were added to the samples at a concentration of $4000 \mathrm{ng} / \mathrm{mL}$ before shaking. In order to minimize the effects of possible contamination in the concentration values, the witness values were subtracted from the sample values and witness correction was applied.

\section{RESUlt AND DisCUSSIONS}

\section{A. Temporal Variation of PAH Concentration in Olive Leaves}

In this study, in order to represent winter, spring, summer and autumn seasons, samples were collected from olive tree leaves on February 01, 2016-March 01, 2016, May 01, 2016-June 01, 2016, July 01, 2016-August 01, 2016 ve November 01, 2016-December 01, 2016, respectively. The temporal variation of the total $12 \mathrm{PAH}\left(\sum 12 \mathrm{PAH}\right)$ concentrations obtained from the study is shown in Figure 1.

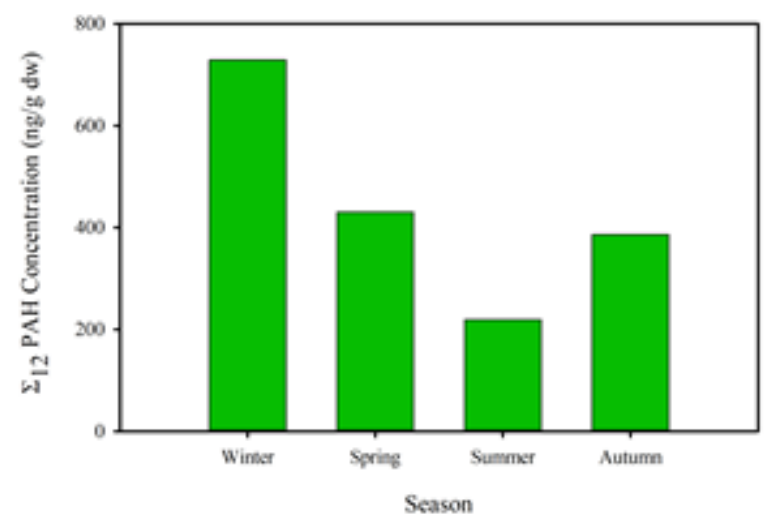

Fig. 1. Seasonal Distribution of the Total PAH Concentrations in Olive Leaf Samples

The mean value of total 12 PAHs ( $\left.\sum 12 \mathrm{PAHs}\right)$ concentrations obtained from leaf samples were 729, 431, 219 and $387 \mathrm{ng} / \mathrm{g}$ dry weight (dw) for winter, spring, summer and autumn seasons, respectively. Different factors including changes in the source types and densities, and meteorological factors (i.e., wind speed, mixing height, solar flux levels, air temperature, etc.) caused the atmospheric PAH fluctuations in winter, spring and autumn seasons [7]. Seasonal variations of PAHs were strongly affected by residential heating in cold months. On the other hand, in summer, in addition to reductions in residential heating, prevailing atmospheric conditions can positively affect PAH distribution and segregation, leading to relatively low PAH levels [8]. Baldantoni et al. (2014) investigated the accumulation of PAH concentrations in olive tree leaves, indicating that PAHs accumulate mostly on leaf surfaces by atmospheric transport and that plant roots do not contribute to PAH concentrations in leaves [9]. Plant organs including roots, leaves, branches and fruits cause the differences in $\mathrm{PAH}$ concentrations in plants [10].

\section{B. Sources Identification of PAHs}

The identification of pollutant sources is an important strategy to understand the contribution levels of the pollutants measured in the atmosphere [11]. The coefficients of divergence (COD) and Pearson correlation coefficient (PCC) are frequently used approach method for the evaluation of pollutants in time with similarities and differences between pollutant sources between two sampling sites and/or two measurement periods [12]. The PCC and COD were calculated as follows;

$$
\begin{gathered}
C O D_{j k}=\sqrt{\frac{1}{p} \sum_{i=1}^{p}\left(\frac{a_{i j}-a_{i k}}{a_{i j}+a_{i k}}\right)^{2}} \\
P C C_{j k}=\frac{\sum_{i=1}^{p}\left(a_{i j}-\bar{a}_{j}\right) x \sum_{i=1}^{p}\left(a_{i k}-\bar{a}_{k}\right)}{\sqrt{\sum_{i=1}^{p}\left(a_{i j}-\bar{a}_{j}\right)^{2} x \sum_{i=1}^{p}\left(a_{i k}-\bar{a}_{k}\right)^{2}}}
\end{gathered}
$$

where ij and ik refer to the average concentration of ith PAH congeners at a different season, $\bar{a}$ is the average PAH 
concentration at seasons, $\mathrm{p}$ is the number of individual $\mathrm{PAH}$ congeners [12]. In general, the COD value is greater than 0.2 , the pollutant sources between two seasons are different. Moreover, the PCC value greater than 0.7 indicates that $\mathrm{PAH}$ concentrations are similar in time [12]. In this study, the COD and $\mathrm{PCC}$ results obtained for olive leaves are shown in Figure 2.

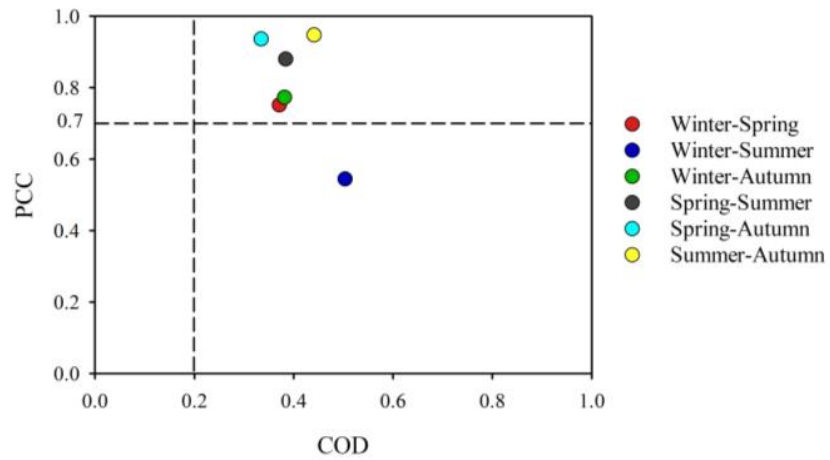

Fig. 2. The coefficients of the Divergence (COD) vs. the Pearson Correlation Coefficient (PCC)

The calculated COD and PCC values showed that the COD values were bigger than 0.2 and the PCC values were higher than 0.7 except for the winter-summer season (Fig. 2). This result demonstrated that the pollutant sources were different among PAH sources in seasons yet PAH concentrations were similar in time except for the winter-summer season. Possible reason for the temporal differences in the winter-summer

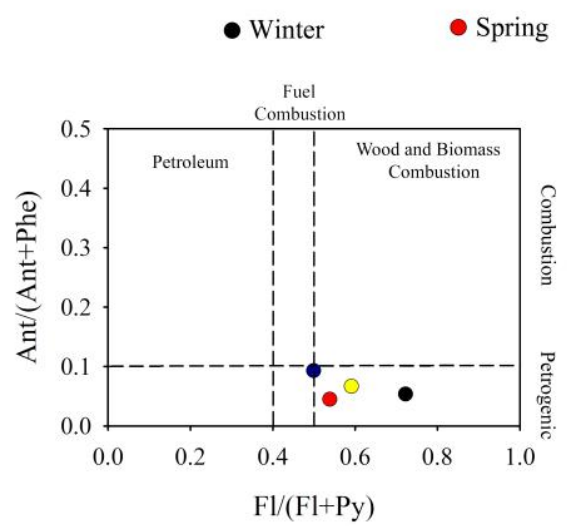

Fig. 3. The Diagnostic Ratios Between Ant/(Ant+Phe)-Fl/(Fl+Py) and IcdP/(IcdP+BghiP)-Fl/(Fl+Py)

Ant and Phe are highly affected by photo-reactions. As a result of this effect, Ant/(Ant+Phe) ratio is very close to 0 value [18]. The presence of high BghiP concentrations means that vehicle emissions prevail in that environment [19]. Similarly, Fl and Py characterize the emissions of oil production, diesel and biodiesel in the environment [18]. The Ant/(Ant+Phe) ratio was smaller than 0.1 in all seasons and it implies that the samples were affected by petrogenic pollution and photo-reactions. In addition, when $\mathrm{Fl} /(\mathrm{Fl}+\mathrm{Py})$ and $\mathrm{IcdP} /(\mathrm{IcdP}+\mathrm{BghiP})$ ratios were examined, they had values of greater than 0.5 in all seasons except for the summer season. The low $\mathrm{Fl} /(\mathrm{Fl}+\mathrm{Py})$ and $\mathrm{IcdP} /(\mathrm{IcdP}+\mathrm{BghiP})$ ratios observed in the summer season demonstrated the vehicle-induced pollution rather than burning

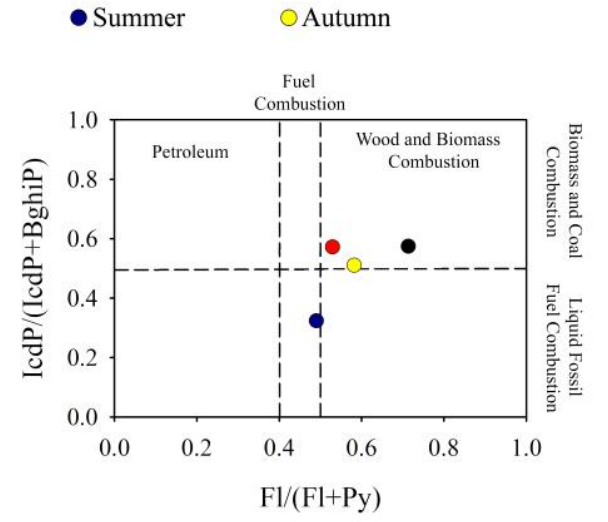

considerations would be the increasing amounts of coal, wood, natural gas and fuel consumed for domestic warming during the winter season [13]. The COD and PCC methods are only used to determine whether the sources are similar and whether they change over time. However, they do not provide information about source identification. Therefore, methods such as the diagnostic ratios (DRs) and principal component analysis (PCA) are used for source identification.

The DRs are a widely used method for identifying the sources of PAHs. The ratio of some types of PAHs to each other and/or total values provides information about possible sources of PAHs [14]. One of the major advantages of this method is that molecular diagnosis rates can be applied to many different sampling materials such as air, water and soil and the calculations are very simple [15]. In many studies in the literature, the DRs have been used to determine the sources of PAHs including mobile, industrial, fuel, agricultural and domestic sources [16]. Generally, the Ant/(Ant+Phe) ratio is used to differentiate between oil and combustion sources; $\mathrm{Fl} /(\mathrm{Fl}+\mathrm{Py})$ ratio is used to differentiate the pollution caused by the combustion of biomass; $\mathrm{IcdP} /(\mathrm{IcdP}+\mathrm{BghiP})$ ratio is used to determine the pollution caused by combustion of fuels [17]. The seasonal DRs obtained in this study are shown in Figure 3.

biomass. In a study (Koçak et al., 2017), it was mentioned that higher PAH emissions were observed by vehicles due to the decrease in heating-related emissions in summer [13]. The PCA analysis is a statistical analysis method that converts a data set into several important explanatory factors or principal components (PCs) that meet most of the variance and emphasize the most important information of the original data set. According to this analysis method, the emission sources of PAHs can be interpreted according to CBs. In general, PCA allows to find the maximum variances in the high dimensional data and project it on a subspace that is equal or less than the original one. However, the lack of fully differentiated emission sources has been shown to be a disadvantage of PCA [20]. The PCA results calculated in this study are shown in Figure 4. 


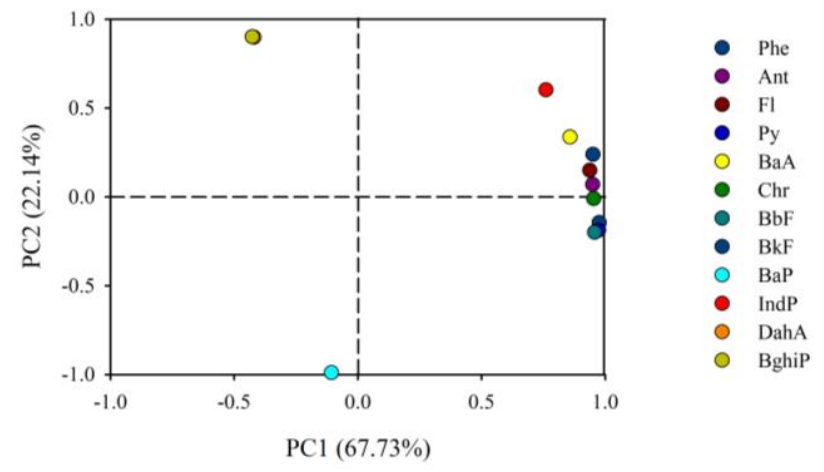

Fig. 4. PCA Results for the Olive Leaves

$89.87 \%$ variance of the scaled data was explained by two factors (PC1 and PC2) for olive leaves during the sampling period. The dominant species in PC1 were 3-, 4-, 5- and 6-ring PAH compounds, which characterize mixed sources [21]. The dominant species in PC2 were BaP, DahA and BghiP. These PAHs characterized oil resources [22]. It was determined that PAH sources, which were determined by both statistical approach methods including the COD and PCC, and traditional source identification methods such as DRs, were different in summer compared to other seasons. The PCA method revealed that vehicles were the most important source of $\mathrm{PAH}$ pollution in the summer. Moreover, the PCA was classified under two factors and PC2 indicated emissions from vehicle emission.

\section{CONCLUSION}

In this study, seasonal concentration levels and possible sources of PAHs were determined with the help of olive tree leaves collected on Gemlik Campus of Bursa Uludag University (Bursa, Turkey) between January-December 2016. The highest PAH concentrations were observed in winter, while the lowest PAH concentrations were observed in summer. This situation was influenced by increasing fossil fuel consumption and meteorological factors such as mixing height, wind speeds, relative humidity in winter while decreases in housing heating were thought to be effective in summer. The coefficient of divergence (COD), Pearson correlation coefficient (PCC), diagnostic ratio (DR), and principal component analysis (PCA) have been used to define the pollutant sources and temporal variation of PAH concentrations. According to these approach methods, it was concluded that there were differences in both temporal distributions and pollutant sources of $\mathrm{PAH}$ concentrations measured in the summer season. Although there are multiple approaches in the literature in which sources of pollutants are identified yet only one method is often chosen. In this study, multiple approaches were applied successfully at the same time.

\section{ACKNOWLEDGMENT}

This study was supported by The Scientific and Technologic Research Council of Turkey (TUBITAK Project No: 114Y577).

\section{REFERENCES}

[1] X. Li, L. Kaattari, M. A. Vogelbein, G. G. Vadas, and M. A. Unger, "A highly sensitive monoclonal antibody based biosensor for quantifying 3-5 ring polycyclic aromatic hydrocarbons (PAHs) in aqueous environmental samples," Physiol. Behav., vol. 176, pp. 139-148, 2017. https://doi.org/10.1016/j.sbsr.2016.02.003

[2] J. A. Silva, N. Ratola, S. Ramos, V. Homem, L. Santos, and A. Alves, “An analytical multi-residue approach for the determination of semi-volatile organic pollutants in pine needles," Anal. Chim. Acta, vol. 858, no. 1, pp. 24-31, 2015. https://doi.org/10.1016/j.aca.2014.12.042

[3] T. A. Tomashuk, T. M. Truong, M. Mantha, and A. E. McGowin, "Atmospheric polycyclic aromatic hydrocarbon profiles and sources in pine needles and particulate matter in Dayton, Ohio, USA," Atmos. Environ., vol. 51, pp. 196-202, 2012. https://doi.org/10.1016/j.atmosenv.2012.01.028

[4] E. Ötvös, I. O. Kozák, J. Fekete, V. K. Sharma, and Z. Tuba, "Atmospheric deposition of polycyclic aromatic hydrocarbons (PAHs) in mosses (Hypnum cupressiforme) in Hungary," Sci. Total Environ., vol. 330, no. 1-3, pp. 89-99, 2004. https://doi.org/10.1016/j.scitotenv.2004.02.019

[5] F. De Nicola et al., "PAH detection in Quercus robur leaves and Pinus pinaster needles: A fast method for biomonitoring purpose," Talanta, vol. 153, pp. 130-137, 2016. https://doi.org/10.1016/j.talanta.2016.01.067

[6] Y. Tasdemir and F. Esen, "Urban air PAHs: Concentrations, temporal changes and gas/particle partitioning at a traffic site in Turkey," Atmos. Res., vol. 84, no. 1, pp. 1-12, 2007. https://doi.org/10.1016/j.atmosres.2006.04.003

[7] B. Cetin, S. Yurdakul, E. Gungormus, F. Ozturk, and S. C. Sofuoglu, "Source apportionment and carcinogenic risk assessment of passive air sampler-derived PAHs and PCBs in a heavily industrialized region," Sci. Total Environ., vol. 633, pp. 30-41, 2018. https://doi.org/10.1016/j.scitotenv.2018.03.145

[8] Y. M. Aydin, M. Kara, Y. Dumanoglu, M. Odabasi, and T. Elbir, "Source apportionment of polycyclic aromatic hydrocarbons (PAHs) and polychlorinated biphenyls (PCBs) in ambient air of an industrial region in Turkey," Atmos. Environ., vol. 97, pp. 271-285, 2014. https://doi.org/10.1016/j.atmosenv.2014.08.032

[9] D. Baldantoni, F. De Nicola, and A. Alfani, "Air biomonitoring of heavy metals and polycyclic aromatic hydrocarbons near a cement plant," Atmos. Pollut. Res., vol. 5, no. 2, pp. 262-269, 2014. https://doi.org/10.5094/APR.2014.032

[10] K. Srogi, "Monitoring of environmental exposure to polycyclic aromatic hydrocarbons: A review," Environ. Chem. Lett., vol. 5, no. 4, pp. 169-195, 2007. https://doi.org/10.1007/s10311-007-0095-0

[11] M. Yadav, K. Soni, B. K. Soni, N. K. Singh, and B. R. Bamniya, "Source apportionment of particulate matter, gaseous pollutants, and volatile organic compounds in a future smart city of India," Urban Clim., vol. 28, no. March, p. 100470, 2019. https://doi.org/10.1016/j.uclim.2019.100470

[12] S. Bano et al., "Coarse particle (PM10-2.5) source profiles for emissions from domestic cooking and industrial process in Central India," Sci. Total Environ., vol. 627, pp. 1137-1145, 2018. https://doi.org/10.1016/j.scitotenv.2018.01.289

[13] E. Koçak, S. Aslan Kılavuz, İ. İmamoğlu, and G. Tuncel, "Ankara'da PM2.5 fraksiyonundaki partiküllerde PAH derişimlerinin ve kaynaklarının belirlenmesi," in VII. Ulusal Hava Kirliliği Ve Kontrolü Sempozyumu, Antalya, 2017, pp. 532-543.

[14] F. Esen and G. Kayıkçı, "Bursa'da iç ve dış mekan hava örneklerinde poliaromatik hidrokrbonların (PAHs) belirlenmesi," Gazi Üniversitesi Mühendislik-Mimarlık Fakültesi Derg., vol. 2018, no. 2018, pp. 1531-1541, 2018. https://doi.org/10.17341/gazimmfd.416449

[15] G. Eker and Y. Tasdemir, "Spatial Variations of Polycyclic Aromatic Hydrocarbon (PAH) Concentrations in the Receiving Water Environment: The Nilüfer Creek," Uludağ Univ. J. Fac. Eng., vol. 21, no. 1, p. 191, 2016. https://doi.org/10.17482/uujfe.01851

[16] G. O. Duodu, K. N. Ogogo, S. Mummullage, F. Harden, A. Goonetilleke, and G. A. Ayoko, "Source apportionment and risk assessment of PAHs in 
Brisbane River sediment, Australia,” Ecol. Indic., vol. 73, pp. 784-799, 2017.

https://doi.org/10.1016/j.ecolind.2016.10.038

[17] X. Gong et al., "Spatial variation of polycyclic aromatic hydrocarbons (PAHs) in surface sediments from rivers in hilly regions of Southern China in the wet and dry seasons," Ecotoxicol. Environ. Saf., vol. 156, no. February, pp. 322-329, 2018.

https://doi.org/10.1016/j.ecoenv.2018.03.004

[18] M. Tobiszewski and J. Namieśnik, "PAH diagnostic ratios for the identification of pollution emission sources," Environ. Pollut., vol. 162, pp. 110-119, 2012. https://doi.org/10.1016/j.envpol.2011.10.025

[19] Y. Marusenko, P. Herckes, and S. J. Hall, "Distribution of polycyclic aromatic hydrocarbons in soils of an arid urban ecosystem," Water. Air. Soil Pollut., vol. 219, no. 1-4, pp. 473-487, 2011. https://doi.org/10.1007/s11270-010-0721-5

[20] D. Cesari et al., "Seasonal variability of PM2.5and PM10composition and sources in an urban background site in Southern Italy," Sci. Total Environ., vol. 612, pp. 202-213, 2018.

https://doi.org/10.1016/j.scitotenv.2017.08.230

[21] D. D. Golobočanin, B. D. Škrbić, and N. R. Miljević, "Principal component analysis for soil contamination with PAHs," Chemom. Intell. Lab. Syst., vol. 72, no. 2, pp. 219-223, 2004. https://doi.org/10.1016/j.chemolab.2004.01.017

[22] D. Agudelo-Castañeda, E. Teixeira, I. Schneider, S. R. Lara, and L. F. O. Silva, "Exposure to polycyclic aromatic hydrocarbons in atmospheric PM1.0 of urban environments: Carcinogenic and mutagenic respiratory health risk by age groups," Environ. Pollut., vol. 224, pp. 158-170, 2017. https://doi.org/10.1016/j.envpol.2017.01.075 